model incorporating presentation core volume, age, and TICI $\geq 2 \mathrm{~B}$ as covariates was constructed. The resulting model was statistically significant $\chi^{2}(2)=22.65,(p<0.001)$ and accounted for $52.9 \%$ of the variance in outcome with a percent accuracy of classification of $85.4 \%$.

Conclusion Presentation volume of diffusion-restricted core was a strong predictor of final infarct volume post-thrombectomy in this cohort of ACLVO patients, whereas time-based covariates showed little if any significant predictive value. For every $1 \mathrm{~mL}$ increase in presentation infarct volume, the odds of a small completed infarct were reduced by about $6 \%$. A presentation core volume $\leq 50 \mathrm{~mL}$ improved the odds of a small final infarct by at least $26 \%$, probably more.

Disclosures B. Cristiano: None. M. Pond: None. S. Basu: None. U. Oyoyo: None. J. Jacobson: 4; C; GeneLux.

\section{0-003 TIME TO STROKE INTERVENTION IS REDUCED WHEN CT ANGIOGRAPHY IS PERFORMED IMMEDIATELY AFTER NON-CONTRAST CT}

${ }^{1} \mathrm{O}$ Zaidat, ${ }^{2} \mathrm{~B}$ Mehta, ${ }^{3} \mathrm{~A}$ Yoo, ${ }^{4} \mathrm{R}$ von Kummer, ${ }^{5} \mathrm{P}$ Khatri, ${ }^{6} \mathrm{R}$ Gupta, ${ }^{7} \mathrm{D}$ Lopes, ${ }^{8} \mathrm{D}$ Frei, ${ }^{9} \mathrm{H}$ Shownkeen, ${ }^{10} \mathrm{D}$ Meyer, ${ }^{10} \mathrm{~V}$ Bach, ${ }^{10} \mathrm{H}$ Buell, ${ }^{10} \mathrm{~S}$ Kuo, ${ }^{10} \mathrm{~A}$ Bose, ${ }^{10} \mathrm{~S}$ Sit, ${ }^{11} \mathrm{~J}$ Mocco. ${ }^{1} \mathrm{St}$ Vincent Mercy Hospital, Toledo, OH; ${ }^{2}$ Memorial Neuroscience Center, Hollywood, FL; ${ }^{3}$ Texas Stroke Institute, Plano, TX; ${ }^{4}$ Universitätsklinikum Carl Gustav Carus, Dresden, Germany; ${ }^{5}$ University of Cincinnati Medical Center, Cincinnati, $\mathrm{OH}_{\text {; }}{ }^{6}$ WellStar Health System, Marietta, GA; ${ }^{7}$ Rush University Medical Center, Chicago, IL; ${ }^{8}$ Swedish Medical Centerid, Englewood, CO; ${ }^{9}$ Central DuPage Hospital, Winfield, IL; ${ }^{10}$ Penumbra, Inc., Alameda, $C A ;{ }^{11}$ Mount Sinai Health System, New York, NY

10.1136/neurintsurg-2016-012589.3
Introduction Imaging still serves as an integral tool for stroke validation and intervention. Limited data is available as to whether performing CTA immediately following non-contrast CT (NCCT) will delay overall treatment time. Centers conducting concurrent NCCT and CTA relative to those performing NCCT alone were evaluated to determine whether having additional imaging extends hospital workflow, prolonging time to IV rtPA and subsequently to endovascular intervention, where warranted.

Materials and methods A total of 108 patients were enrolled in the THERAPY trial, a randomized controlled trial designed to assess the benefits of adjunctive mechanical thrombectomy plus IV rtPA versus IV rtPA alone. Standard emergency department (ED) protocols for participating centers are registered as either conducting concurrent NCCT and CTA $(\mathrm{N}=22)$ or postponed acquisition of CTA $(\mathrm{N}=13)$. The effects of having concurrent imaging modalities are evaluated for all patients as well as singly for patients undergoing endovascular therapy.

Results Patients having the relevant data for analysis totaled 105 amongst 35 centers. Sixty-six patients received concurrent imaging processes across 22 centers, while 39 patients between 13 centers received sequential NCCT and CTA imaging.

For all patients, clear benefits of having both NCCT and CTA in conjunction were a reduction in time from presentation at the ED to randomization, and consequently from onset to randomization (Table 1). No significance difference in time was observed from admission to IV rtPA administration in this population.

More significant differences were observed in the EVT cohort, including a reduction in the time from presentation to

Abstract 0-003 Table 1 Separate and concurrent NCCT/CTA angiography-related hospital processing times

\begin{tabular}{|c|c|c|c|}
\hline $\begin{array}{l}\text { Characteristic (minutes) } \\
\text { Mean (SD) }\end{array}$ & $\begin{array}{l}\text { Separate NCCT and } \\
\text { CTA Acquisition }\end{array}$ & $\begin{array}{l}\text { Concurrent NCCT } \\
\text { and CTA Acquisition }\end{array}$ & $P$ - value* \\
\hline \multicolumn{4}{|c|}{ Study Cohort } \\
\hline & $n=39$ & $n=66$ & \\
\hline Onset to ED & $96.6(83.9)$ & $79.4(56.9)$ & 0.57 \\
\hline Onset to Clot ID - NCCT picture & $109.3(69.7)$ & $100.5(60.8)$ & 0.57 \\
\hline Onset to Baseline CTA & $176.6(77.3)$ & $112.1(72.1)$ & $<0.001$ \\
\hline ED to Baseline CTA & $82.9(78.4)$ & $35.1(38.2)$ & 0.002 \\
\hline ED to Randomization & $111.0(54.6)$ & $88.2(35.4)$ & 0.04 \\
\hline Onset to Randomization & $207.7(59.3)$ & $167.5(58.0)$ & $<0.001$ \\
\hline ED to IV rt-PA & $29.1(63.1)$ & $35.3(35.3)$ & 0.53 \\
\hline Onset to IV rt-PA & $125.9(52.6)$ & $114.7(51.0)$ & 0.19 \\
\hline Revascularization to $\mathrm{mTICl} 2 \mathrm{~b} / 3$ & N/A & N/A & N/A \\
\hline 90-day mRS 0-2 & $27.8 \%(10 / 36)$ & $38.6 \%(22 / 57)$ & 0.37 \\
\hline \multicolumn{4}{|c|}{ Endovascular Treatment Group } \\
\hline & $(n=18)$ & $(n=33)$ & \\
\hline ED to Arterial Access & $161.2(59.4)$ & $120.7(48.7)$ & 0.01 \\
\hline Onset to Arterial Access & $244.6(38.5)$ & $212.1(71.1)$ & 0.07 \\
\hline ED to Pump on & $196.6(60.5)$ & $138.8(51.2)$ & 0.003 \\
\hline Onset to Initial Pump on & $277.2(38.0)$ & $227.0(70.2)$ & 0.04 \\
\hline Arterial Access to Final Angiography & $85.5(85.5)$ & $62.8(41.2)$ & 0.26 \\
\hline Onset to Final Angiography & $328.9(72.8)$ & $267.2(83.1)$ & 0.01 \\
\hline Revascularization to $\mathrm{mTICl} 2 \mathrm{~b} / 3$ & $52.9 \%(9 / 17)$ & $85.2 \%(23 / 27)$ & 0.04 \\
\hline 90-day mRS 0-2 & $36.8 \%(7 / 19)$ & $40.0 \%(12 / 30)$ & 1.0 \\
\hline
\end{tabular}

* Analysis was performed either by the Wilcoxon signed-rank test or Fisher's Exact Test. 
arterial access of roughly 40 minutes $(p=0.01)$ for patients having NCCT and CTA performed concurrently. As a result, downstream effects of the procedure demonstrated a reduction in time from presentation to aspiration thrombectomy initiation, from onset to aspiration, and from onset to final angiography (all $\mathrm{p}<0.05$ ). Notably, these patients demonstrated a higher rate of revascularization to mTICI $2 b-3(p=0.04)$.

Conclusion The effects on procedural and clinical outcome of having combined imaging efforts were less apparent in the entire cohort relative to the EVT cohort. These results suggest having concurrent NCCT and CTA imaging improves time from presentation to endovascular therapy, without significant delay to IV rtPA infusion. More patients were observed to achieve mTICI 2 b-3 if both imaging procedures were obtained in conjunction, possibly as a result of the reduction in time to endovascular intervention in this cohort. Further data from a larger sample size will help validate these findings.

Disclosures O. Zaidat: 6; C; Penumbra, Inc.. B. Mehta: None. A. Yoo: 1; C; National Institute of Health, Penumbra, Inc., Remedy Pharmaceuticals. R. von Kummer: 2; C; Penumbra, Inc. P. Khatri: 1; C; Penumbra, Inc. R. Gupta: 6; C; Penumbra, Inc. D. Lopes: 6; C; Penumbra, Inc. D. Frei: 3; C; Penumbra, Inc.. 6; C; Penumbra, Inc.. H. Shownkeen: None. D. Meyer: 5; C; Penumbra, Inc. V. Bach: 5; C; Penumbra, Inc. H. Buell: 5; C; Penumbra, Inc. S. Kuo: 5; C; Penumbra, Inc. A. Bose: 4; C; Penumbra, Inc.. 5; C; Penumbra, Inc. S. Sit: 4; C; Penumbra, Inc.. 5; C; Penumbra, Inc. J. Mocco: 1; C; Penumbra, Inc.

\section{0-004 ANALYSIS OF M2 OCCLUSIONS WITHIN TREVO ACUTE ISCHEMIC STROKE (TRACK) STENT-RETRIEVER THROMBECTOMY REGISTRY}

${ }^{1} \mathrm{~A}$ Castonguay, ${ }^{2} \mathrm{R}$ Nogueira, ${ }^{3} \mathrm{~J}$ English, ${ }^{4} \mathrm{~S}$ Satti, ${ }^{5} \mathrm{H}$ Farid, ${ }^{6} \mathrm{E}$ Veznedaroglu, ${ }^{6} \mathrm{M}$ Binning, ${ }^{7} \mathrm{~A}$ Puri, ${ }^{8} \mathrm{~N}$ Vora, ${ }^{8} \mathrm{R}$ Budzik, ${ }^{9} \mathrm{G}$ Dabus, ${ }^{9}$ I Linfante, ${ }^{10} \mathrm{~V}$ Janardhan, ${ }^{11} \mathrm{~A}$ Alshekhlee, ${ }^{12} \mathrm{M}$ Abraham, ${ }^{13} \mathrm{R}$ Edgell, ${ }^{14} \mathrm{M}$ Taqi, ${ }^{15} \mathrm{R}$ El Khoury, ${ }^{16} \mathrm{M}$ Mokin, ${ }^{16} \mathrm{M}$ Mokin, ${ }^{17} \mathrm{~A}$ Majjhoo, ${ }^{18} \mathrm{M}$ Kabbani, ${ }^{19} \mathrm{M}$ Froehler, ${ }^{20}$ I Finch, ${ }^{21} \mathrm{~S}$ Ansari, ${ }^{22} \mathrm{R}$ Novakovic, ${ }^{23} \mathrm{~T}$ Nguyen, ${ }^{1} \mathrm{O}$ Zaidat. ${ }^{1}$ St. Vincent Mercy Medical Center, Toledo, OH; ${ }^{2}$ Emory University School of Medicine, Atlanta, GA; ${ }^{3}$ California Pacific Medical Center, San Francisco, $C A_{;}{ }^{4}$ Christiana Care Health System, Newark, DE; ${ }^{5}$ St. Jude Medical Center, Fullerton, $C A ;{ }^{6}$ Drexel Neurosciences Institute, Philadelphia, PA; 'University of Massachusetts Medical School, Boston, MA; ${ }^{8}$ Riverside Radiology, Columbus, OH; ${ }^{9}$ Baptist Cardiac and Vascular Institute, Miami, FL; ${ }^{10}$ Texas Stroke Institute, Plano, TX; ${ }^{11}$ DePaul Stroke Center-SSM Neuroscience Institutes, St. Louis, MO; ${ }^{12}$ University of Kansas Medical Center, Kansas City, KS; ${ }^{13}$ St. Louis University, St. Louis, MO; ${ }^{14}$ Los Robles Hospital and Medical Center, Thousand Oaks, CA; ${ }^{15}$ Tulane University, New Orleans, LA; ${ }^{16}$ University of South Florida, Tampa, $F L_{;}{ }^{17}$ Wayne State School of Medicine, Detroit, MI; ${ }^{18}$ Gundersen Health System, La Crosse, WI; ${ }^{19}$ Vanderbilt University Medical Center, Nashville, TN; ${ }^{20}$ John Muir Health, Walnut Creek, CA; ${ }^{21}$ Northwestern University, Feinberg School of Medicine, Chicago, IL; ${ }^{22}$ UT Southwestern Medical Center, Dallas, TX; ${ }^{23}$ Boston Medical Center, Boston, MA

\subsection{6/neurintsurg-2016-012589.4}

Background and purpose Several recent randomized clinical trials have demonstrated the safety and efficacy of mechanical thrombectomy with stent retrievers for acute ischemic stroke patients with anterior circulation occlusions. However, these trials have limited enrollment of patients with M2 occlusions. Here, we sought to examine the clinical and angiographic outcomes of patients with M2 occlusions in the Trevo Acute Ischemic Stroke (TRACK) stent-retriever thrombectomy multicenter registry.
Methods Data from the investigator-initiated TRACK Registry (631 consecutive AIS patients, 23 clinical centers) was used to examine and compare demographic, clinical, and angiographic outcomes of patients with M1 versus M2 occlusions who were treated with TREVO as first treatment device.

Results Of the 631 patients enrolled in the TRACK registry, $84(13.3 \%)$ had M2 and 344 (54.5\%) had M1 occlusions. Mean age was similar between the M1 and M2 cohorts, $66.5 \pm 14.4$ and $64.7 \pm 3.8$ years $(\mathrm{p}=0.34)$, respectively. M2 patients had a lower median baseline NIHSS at presentation (14 (IQR 7-9) versus 18(IQR 14-22), p $\leq 0.0001)$. Time of onset to groin puncture $(347 \pm 237.4$ and $361 \pm 232.3$, $\mathrm{p}=0.63)$ and total procedural time (85.9 \pm 49.9 and $78.3 \pm 64.5, \mathrm{p}=0.4)$ was similar between the M1 and M2 cohorts. The number of passes with TREVO device was greater in the M1 cohort (Median, 2 (IQR 1-3) versus 1(IQR $1-2), p=0.01)$ as well as use of rescue therapy $(20.2 \%$ versus $9.8 \%, p=0.03)$. Patients with M2 occlusions achieved a higher rate of TICI 3 revascularization after the $1^{\text {st }}$ pass with TREVO device compared to those with M1 occlusions $55.8 \%$ versus $40.4 \%, \mathrm{p}=0.01)$. There was no significant difference in time to revascularization $(78.6 \pm 50.7$ versus $71.6 \pm 45.3$, $\mathrm{p}=0.2)$, revascularization success $(\geq$ TICI 2 b) $(80.5 \%$ versus $76.2 \%, \mathrm{p}=0.4)$, symptomatic intracranial hemorrhage $(5.6 \%$ versus $6.0 \%, \mathrm{p}=0.9), 90$ day modified Rankin Scale score $0-2(51.0 \%$ versus $57.4 \%, \mathrm{p}=0.35)$, or mortality $(16.1 \%$ versus $13.2 \%, \mathrm{p}=0.6$ ) between the M1 and M2 groups, respectively.

Conclusions Patients with M2 Occlusions are more likely to achieve complete recanalization from the first pass with Trevo stent retriever device than M1 occlusion. In addition, the M2 cohort had a numerically higher rate of good clinical outcome and less rate of mortality than M1 group. This substudy is limited by lack of a control M2 group without mechanical thrombectomy.

Disclosures A. Castonguay: None. R. Nogueira: None. J. English: None. S. Satti: None. H. Farid: None. E. Veznedaroglu: None. M. Binning: None. A. Puri: None. N. Vora: None. R. Budzik: None. G. Dabus: None. I. Linfante: None. V. Janardhan: None. A. Alshekhlee: None. M. Abraham: None. R. Edgell: None. M. Taqi: None. R. El Khoury: None. M. Mokin: None. M. Mokin: None. A. Majjhoo: None. M. Kabbani: None. M. Froehler: None. I. Finch: None. S. Ansari: None. R. Novakovic: None. T. Nguyen: None. O. Zaidat: None.

\section{0-005 INFLUENCE OF BALLOON, CONVENTIONAL, OR DISTAL CATHETERS ON ANGIOGRAPHIC AND TECHNICAL OUTCOMES IN STRATIS}

${ }^{1} \mathrm{O}$ Zaidat, ${ }^{2} \mathrm{D}$ Liebeskind, ${ }^{3} \mathrm{R}$ Jahan, ${ }^{4} \mathrm{M}$ Froehler, ${ }^{5} \mathrm{M}$ Aziz-Sultan, ${ }^{6} \mathrm{R}$ Klucznik, ${ }^{7} \mathrm{~J}$ Saver, ${ }^{8} \mathrm{D}$ Yavagal, ${ }^{9} \mathrm{~N}$ Mueller-Kronast. ${ }^{1}$ Neuroscience and Stroke Programs, St Vincent Mercy Medical Center, Toledo, $\mathrm{OH}^{2}{ }^{2}$ Neurovascular Imaging Research Core, University of California Los Angeles, Los Angeles, CA; ${ }^{3}$ Division of Interventional Neuroradiology, University of California Los Angeles, Los Angeles, CA; ${ }^{4}$ Cerebrovascular Program, Vanderbilt University Medical Center, Nashville, TN; ${ }^{5}$ Department of Neurosurgery, Brigham and Women's Hospital, Boston, MA; ${ }^{6}$ Department of Radiology, Methodist Hospital, Houston, TX; ${ }^{7}$ Department of Neurology and Comprehensive Stroke Center, University of California Los Angeles, Los Angeles, CA; ${ }^{8}$ Department of Neurology and Neurosurgery, University of Miami/Jackson Memorial Hospital, Miami, FL; ${ }^{9}$ Neurointervention Department, Delray Medical Center/Tenet South Florida, Delray Beach, FL 